\title{
A gestão de resíduos sólidos no Nordeste Urbano
}

\author{
Solid waste management in urban Brazilian Northeast \\ Géstion de resíduos sólidos en el Noroeste Urbano
}

Recebido: 14/08/2021 | Revisado: 19/08/2021 | Aceito: 26/08/2021 | Publicado: 29/08/2021

\author{
Navilta Veras do Nascimento \\ ORCID: https://orcid.org/0000-0002-2181-4551 \\ Faculdade Luciano Feijão, Brasil \\ E-mail: naviltaveras@gmail.com \\ Francisco Rayan Gomes Lima \\ ORCID: https://orcid.org/0000-0002-5987-8585 \\ Faculdade Luciano Feijão, Brasil \\ E-mail: rayangomes64@gmail.com \\ Francisco Farrapo Portela \\ ORCID: https://orcid.org/0000-0001-7718-2832 \\ Faculdade Luciano Feijão, Brasil \\ E-mail: cielito_port@hotmail.com \\ José Levi Chaves de Sousa \\ ORCID: https://orcid.org/0000-0003-2174-1863 \\ Faculdade Luciano Feijão, Brasil \\ E-mail: levichaves1@ hotmail.com \\ Clovis Aires Correia Junior \\ ORCID: https://orcid.org/0000-0003-2460-2981 \\ Centro Universitário Mauricio de Nassau, Brasil \\ E-mail: clovis.aires88@gmail.com
}

\begin{abstract}
Resumo
O resíduo sólido é um dos materiais descartáveis bastante empregado em todo o Nordeste urbano, e ele tem um valor imprescindível para o público consumidor, o seu emprego requer responsabilidade e consciência no manejo. Dados fornecidos pelo observatório dos lixões da Confederação Nacional dos Municípios (CNM) estimam que há cerca de 898 em números de lixões e aterros controlados na região Nordeste. No presente artigo nos ateremos aos resíduos sólidos das microrregiões da Paraíba e do Ceará. E assim, apontar diretrizes para que o disposto na Lei Federal $\mathrm{n}^{\circ}$ 12.305/2010 que instituiu a PNRS. Possa ser empregado na prática. Essas diretrizes estipulam o prazo esgotado para os municípios, ressalta as técnicas usadas, a importância do planejamento, a preocupação com o aspecto financeiro, organiza datas, contribui para a formação de ideias, norteia práticas de segurança, ao mesmo tempo, a realidade no âmbito da gestão de resíduos sólidos requer a adoção de uma perspectiva holística, o que proporciona um olhar crítico-reflexivo sobre o uso consciente do lixo, a fim de minimizar impactos socioambientais. Com o estudo foi possível constatar a necessidade de políticas públicas efetivas, e a adoção de uma política institucional, adoção curricular nas escolas através de uma maior informação, isso é possível por meio de uma propaganda educativa, e também de fóruns de conhecimento com o fito de proporcionar maior conscientização acerca do problema, e assim mitigar impactos e proporcionar a adoção de estratégias eficazes. Através das ações supracitadas a geração de empregos será impactada positivamente, e haverá uma maior conscientização ambiental, a adoção dessas medidas também colabora para salubridade, pois o descarte incorreto gera impactos na saúde das populações estudadas. Diante do contexto, projetos e práticas são desafios importantes para o futuro, mas as mudanças requerem a implementação da gestão de resíduos sólidos junto às populações estudadas.
\end{abstract}

Palavras-chave: Sustentabilidade; Gestão; Resíduo sólido consumido.

\begin{abstract}
Solid waste is one of the disposable materials widely used throughout the urban Northeast, and it has an essential value for the consuming public, its use requires responsibility and awareness in handling. Data provided by the National Confederation of Municipalities (CNM) dumps observatory estimate that there are about 898 in numbers of dumps and landfills controlled in the Northeast region. In this article we will focus on solid waste from the microregions of Paraíba and Ceará. And so, point out guidelines for the provisions of Federal Law No. 12,305/2010 that instituted the PNRS. Can be used in practice. These guidelines stipulate the deadline for municipalities, highlight the techniques used, the importance of planning, concern with the financial aspect, organize dates, contribute to the formation of ideas, guide safety practices, at the same time, the reality in the context solid waste management requires the adoption of a holistic perspective, which provides a critical and reflective look at the conscientious use of waste, in order to minimize social and environmental impacts. With the study, it was possible to verify the need for effective
\end{abstract}


public policies, and the adoption of an institutional policy, curriculum adoption in schools through more information, this is possible through educational advertising, and also through knowledge forums with the aim to provide greater awareness of the problem, and thus mitigate impacts and provide the adoption of effective strategies. Through the aforementioned actions, the generation of jobs will be positively impacted, and there will be greater environmental awareness, the adoption of these measures also contributes to health, as incorrect disposal generates impacts on the health of the populations studied. Given the context, projects and practices are important challenges for the future, but changes require the implementation of solid waste management with the populations studied.

Keywords: Sustainability; Management; Solid waste consumed.

\begin{abstract}
Resumen
Los residuos sólidos son uno de los materiales desechables más utilizados en todo el Nordeste urbano, y tienen un valor fundamental para el público consumidor, su uso requiere responsabilidad y conciencia en su manejo. Los datos proporcionados por el observatorio de vertederos de la Confederación Nacional de Municipios (CNM) estiman que hay alrededor de 898 en número de vertederos y vertederos controlados en la región Nordeste. En este artículo nos centraremos en los residuos sólidos de las microrregiones de Paraíba y Ceará. Y así, señale lineamientos para lo dispuesto en la Ley Federal N ${ }^{\circ} 12.305$ / 2010 que instituyó el PNRS. Se puede utilizar en la práctica. Estos lineamientos estipulan el plazo para los municipios, resaltan las técnicas empleadas, la importancia de la planificación, la preocupación por el aspecto financiero, organizan fechas, contribuyen a la formación de ideas, orientan prácticas de seguridad, al mismo tiempo, la realidad en el contexto de residuos sólidos. La gestión requiere la adopción de una perspectiva holística, que brinde una mirada crítica y reflexiva sobre el uso consciente de los residuos, con el fin de minimizar los impactos sociales y ambientales. Con el estudio se pudo constatar la necesidad de políticas públicas efectivas, y la adopción de una política institucional, la adopción curricular en las escuelas a través de más información, esto es posible a través de la publicidad educativa, y también a través de foros de conocimiento con el objetivo de brindar mayor conciencia del problema, y así mitigar impactos y brindar la adopción de estrategias efectivas. A través de las acciones antes mencionadas, se impactará positivamente la generación de empleo, y habrá mayor conciencia ambiental, la adopción de estas medidas también contribuye a la salud, ya que la disposición incorrecta genera impactos en la salud de las poblaciones estudiadas. Dado el contexto, los proyectos y las prácticas son desafíos importantes para el futuro, pero los cambios requieren la implementación de un manejo de residuos sólidos con las poblaciones estudiadas.
\end{abstract}

Palabras clave: Sustentabilidad; Administración; Residuos sólidos consumidos.

\title{
1. Introdução
}

O problema relacionado ao descarte de resíduos sólidos não é um problema recente, uma sucinta análise a partir de uma perspectiva histórica nos possibilita ver que o problema do descarte de lixo não é algo recente, pois na Pré-história a humanidade já produzia lixo, só que em proporções menores, e, por conseguinte com impactos menores. Antes do sedentarismo, os povos nômades a cada migração deixavam seu lixo que era decomposto em virtude da ação do tempo (Oliveira, 2018).

$\mathrm{Na}$ Antiguidade, Jerusalém já sofria com o lixo produzido, como era uma cidade cercada de muralhas, e o lixo podia servir como uma rampa para invasores, os antigos judeus tiveram a ideia de queimar o lixo com enxofre nas adjacências da muralha, restos de animais e cadáveres de pessoas que segundo a religião judaica eram consideradas impuras eram queimados no Vale de Hinom (Geena), o fogo era continuamente alimentado (Rusconi, 2005)

É um fato bastante conhecido que no século XIV, durante a Idade Média, o lixo possibilitou a proliferação de ratos negros e pulgas, e essas transmitiram uma doença chamada peste bubônica ou peste negra (Yersinia pestis), cerca de 1/3 da população da Europa foi dizimada pela peste negra, também cabe destacar que cerca de 24 milhões morreram no Oriente em decorrência da peste. (Rezende, 2009).

$\mathrm{Na}$ Idade Moderna, a Europa e mais tarde os Estados Unidos experimentaram uma mudança sem precedentes nunca antes vista na história causada pelo advento da indústria, a Europa predominantemente rural passou a habitar ambientes urbanos, a produção de bens de consumo crescera de modo vertiginoso, e essas cidades sofrem com o inchaço populacional, sem uma infraestrutura adequada para comportar a população, a higiene precária bem como outros problemas de cunho social possibilitam a disseminação de doenças em virtude dos resíduos sólidos, descartados incorretamente (Oliveira, 2018). 
Um olhar voltado para a história do Brasil permite perceber que o uso de resíduos sólidos de modo incorreto acompanhará as ações do colonizador, pois os povos indígenas mantêm uma relação harmoniosa com o meio ambiente. O problema com os resíduos sólidos verifica-se com mais intensidade a partir do século XIX, péssimos hábitos de higiene no início da República aliados à ação de ratos e mosquitos fez com que o Rio de Janeiro, então capital federal sofresse com a varíola, febre amarela e peste bubônica, medidas sanitizantes do presidente Rodrigues Alves e do médico Oswaldo Cruz culminaram com a maior revolução urbana do país, chamada de a Revolta da Vacina (Bueno, 2013).

$\mathrm{Na}$ Idade Contemporânea muitos aspectos mudaram positivamente em relação à gestão de resíduos sólidos, mas mesmo com um amplo leque de informações, o uso incorreto dos resíduos sólidos é um grave problema que afeta as cidades. No atual contexto, a reciclagem desempenha um papel central na gestão integrada de resíduos, uma vez que aborda todo o ciclo de recuperação destes. A reciclagem tem princípio com a coleta de materiais, esses materiais coletados serão transformados em insumos ou novos produtos (Brasil, 2019).

No Nordeste há a necessidade de se trabalhar de modo efetivo a gestão de resíduos sólidos para minimizar problemas socioambientais, gerar empregos e o mais relevante, despertar a consciência e olhar crítico sobre essa questão tão relevante para o sucesso da região mais precária do Brasil. Tendo em consideração os diversos problemas oriundos da gestão de resíduos sólidos incorreta ou até mesmo, inexistente em alguns casos.

A Constituição Federal (CF) de 1988 trouxe muitas inovações em prol da gestão de resíduos sólidos, a nova configuração influenciou a implementação de políticas públicas de cunho universal (Mello, 2020). Além disso, a Carta Magna possibilitou uma maior participação dos municípios na implementação de políticas públicas diversas. Essa maior autonomia municipal foi acompanhada de desafios, tais como limitações técnicas, orçamentárias ou em relação ao arranjo da gestão (Mello, 2020).

Essas mudanças políticas que destoam da realidade estrutural dos municípios impossibilitaram aos municípios o cumprimento dos prazos legais determinados, e muito deles não foram capazes de acabar com os lixões e aterros controlados, nem mesmo de elaborar planos municipais de GIRS (Gestão Integrada de Resíduos Sólidos). Dados fornecidos pela Confederação Nacional dos Municípios (CNM, 2017), mostram um percentual de 38,2\% dos municípios que conseguiram elaborar os seus Planos Municipais de Gestão Integrada de Resíduos Sólidos, também cabe destacar que apenas 47,5\% dos municípios dispõe de aterros sanitários, um número insatisfatório e que escancara os problemas relacionados ao ambiente urbano e sua relação com o meio ambiente, esses números revelam a precariedade infraestrutural da maioria dos municípios, e que implica na necessidade de políticas e ações voltadas à gestão de resíduos sólidos e sua implementação, mas que levem em consideração o real contexto em que os municípios estão imersos.

Os parâmetros em relação à gestão de resíduos sólidos no âmbito nacional são estipulados pela PNRS (Plano Nacional de Resíduos Sólidos), ele é responsável por nortear as responsabilidades, princípios e fins relacionados à implementação da gestão de resíduos sólidos no Brasil. A lei é de fundamental importância na condução da implementação dos resíduos sólidos e visa promover avanços em relação à gestão dos resíduos, as diferentes esferas do poder público e o setor empresarial convergem para um mesmo fim legal. (Brasil, 2020).

A Gestão dos Resíduos Sólidos é muito relevante atualmente por cumprir um papel socioambiental, ela está voltada às necessidades do futuro, contemplando a segurança e a saúde da população que muitas vezes não está a par de seus direitos e deveres. Neste contexto, questões que visam mitigar problemas são suscitadas, sobretudo no tocante às populações carentes que serão positivamente impactadas. 


\section{Metodologia}

O presente trabalho está embasado em bibliografias revisadas que tratam do tema de gestão de resíduos sólidos, portanto, trata-se de uma pesquisa bibliográfica, para segundo Severiano (2016) em relação à natureza da pesquisa, a pesquisa bibliográfica é aquela realizada a partir de registro disponível, produto de trabalhos anteriores, consultados em livros, artigos, teses etc. Assim, dados de outras pesquisas ou outras categorias teóricas já desenvolvidas são utilizadas, assim os textos que fornecem esse aporte tornam-se fontes a serem pesquisadas, destarte, desenvolvemos o presente estudo a partir de estudos anteriores, quanto à abordagem, este estudo pode ser classificado como qualitativo. Ludke e Andre (2013) elencam alguns pontos característicos da abordagem qualitativa: 1) ocorre no ambiente natural, ou o pesquisador é o principal instrumento; 2) os dados obtidos são preferencialmente descritivos; 3) a preocupação quanto ao processo sobrepõe-se à preocupação quanto ao produto; 4) o significado projetado sobre coisas e vida são focos de atenção para o pesquisador; 5) a análise de dados e informações inclina-se a um processo indutivo esses trabalhos justificam a necessidade de discussão do tema proposto, para tanto, consultamos com acuidade artigos de revisão e técnicos, periódicos e sites.

Tendo em consideração essa contextualização, visamos, pois, suscitar pontos críticos a fim de mitigar ou até mesmo extinguir problemas da gestão de resíduos sólidos no semiárido nordestino, pois o Nordeste é a região que apresenta mais urgência no tocante à gestão de resíduos sólidos. Ao longo do trabalho muitas questões são levantadas em relação à PNRS, RSU, reciclagem, aspectos socioambientais, também no tocante à União, estados, municípios e comunidades que devem estar integrados com o mesmo escopo.

No alarmante cenário onde se sobressai a desinformação e a gestão inadequada de resíduos sólidos a elaboração de algumas leis fomentaram uma maior responsabilidade do Poder Público e da sociedade, destacamos a lei 12.305 de agosto de 2010, ela instituiu a Política Nacional de Resíduos Sólidos, ela contém princípios, objetivos e diretrizes para regulamentar a gestão integrada de resíduos sólidos, promovendo maior articulação e integração de pessoas físicas e jurídicas, tanto do direito público quanto do privado, a responsabilidade compartilhada ( Freitas et al., 2017).

No artigo 12 são determinadas informações acerca do Sistema Nacional de Informações sobre a Gestão de Resíduos Sólidos (SINIR), sistema que deverá ser organizado e mantido pela União, Estados e Municípios (Brasil, 2010).

Silveira e Clementino (2017) destacam os desafios em relação à gestão de resíduos sólidos nos municípios brasileiros, dentre os maiores gargalos os autores destacam a dificuldade financeira dos municípios atrelada à incapacidade técnica em relação à PNRS. Vale destacar também as dificuldades em relação à disposição final correta de resíduos sólidos e a elaboração de planos de gestão (Silveira; Clementino, 2007, p.15).

Devido a isso, a PNRS instituiu prazos para que os Municípios se enquadrassem nas diretrizes da Lei. Nesses termos, dispõe que

Art. 54. A disposição final ambientalmente apropriada dos rejeitos, observado o disposto no $§ 1$ o do art. 9 o, deverá ser implantada em até 4 (quatro) anos após a data de publicação desta Lei. Art. 55. O disposto nos arts. 16 e 18 entra em vigor 2 (dois) anos após a data de publicação desta Lei. Art. 56. A logística reversa relativa aos produtos de que tratam os incisos V e VI do caput do art. 33 será implementada progressivamente segundo cronograma estabelecido em regulamento.

Não obstante a previsão legal, verifica-se que os municípios brasileiros, especialmente aqueles de pequeno e médio porte, encontraram problemas na implementação da PNRS. Por exemplo, destaca-se o município de Várzea Alegre - CE, objeto do estudo, que não possuía as condições necessárias para consolidar as atividades de planejamento, fiscalização e tratamento dos resíduos sólidos na configuração determinada pela Lei, sobretudo pela carência de recursos financeiros. (Souza,2019) 
Em virtude disso, foram realizados esforços no sentido de adotar a gestão consorciada como uma opção viável a fim de atender às exigências da Lei n ${ }^{\circ}$ 12.305/10 e, no ano de 2018, os municípios de Várzea Alegre, Baixio, Cedro, Granjeiro, Ipaumirim, Lavras da Mangabeira e Umari, todos no estado do Ceará, se integraram para a formação do Consórcio Público de Manejo de Resíduos Sólidos da Região Centro Sul (Ceará, 2017).

Em suma, a lei instituiu prazo de 4 anos para o fechamento dos lixões e de 2 anos para a elaboração dos planos referidos, os quais foram ignorados em muitos municípios. Em 2015 o senado aprovou o Projeto de Lei 425/2014 prorrogando o prazo para encerramento dos lixões de acordo com o tamanho populacional.

A Lei no 1.038/18 ratificou o Protocolo de Intenções no Município de Várzea Alegre, instituiu como sendo uma de suas diretrizes básicas, isto é, cabe aos Municípios Consorciados o dever de elaborar planos regionais associados de limpeza urbana e manejo de resíduos sólidos na área de atuação do Consórcio, esses planos devem ser formados com horizonte mínimo de 20 (anos), revisados a cada 4 (quatro). Pois é também uma exigência da Lei Federal 12.305/2010. (Souza,2019)

Dados obtidos para a construção do Plano Nacional de Resíduos Sólidos (BRASIL, 2020) corroboram que a maior parte de resíduos urbanos produzidos no Brasil são constituídos por matéria orgânica (cerca de 50\% do total), seguido pelo material seco (cerca de 32\%). No entanto, esta matéria orgânica é frequentemente descartada misturada a outros resíduos, o que torna inviável ações específicas para o seu bom emprego e para o aproveitamento das outras matérias, prejudicando outras ações como por exemplo os programas de reciclagem (Brasil, 2020).

Dados de estudo pela Associação Brasileira de Empresas de Limpeza Pública e Resíduos Especiais (Abrelpe) mostram que no ano de 2018 foram produzidos no Brasil cerca de 79 milhões de toneladas de resíduos sólidos, o que equivale a uma produção per capita anual de $380 \mathrm{~kg}$ ou a uma produção diária de pouco mais de $1 \mathrm{~kg}$. Sendo que desse total, apenas 92\% foi coletado (Abrelpe, 2019)

Portanto, cabe destacar que os índices relativos à coleta são altos, mas apesar disso, representam cerca de 6,3 milhões de toneladas de resíduos descartados de modo irregular em locais inapropriados como o que ocorre, por exemplo, nos lixões ou aterros controlados. Esses lugares não possuem sistema adequados para a recepção dos resíduos, eles provocam danos a nível socioambiental. Um outro ponto a ser melhorado, diz respeito à coleta desse lixo, pois somente uma parte será destinada corretamente (Abrelpe, 2019).

Um outro trabalho que remete ao presente estudo, e que serviu para embasar este artigo foi o estudo realizado por Oliveira e Júnior (2016), eles fizeram uma minuciosa análise dos Planos Municipais de Gestão Integrada de Resíduos Sólidos em relação ao conteúdo previsto na Lei $\mathrm{n}^{\circ}$ 12.305/2010, quanto à implantação da coleta seletiva. Para atingir o escopo do estudo aludido, 17 planos de municípios com população acima de 200 mil habitantes foram analisados. Apesar de os planos refletirem positivamente o desejo de mudanças e aumento da escala conferida ao serviço prestado, eles concluíram que a maior parte da amostra estudada não apresentou adesão em relação a aspectos indispensáveis na gestão de resíduos sólidos como a coleta seletiva e a reciclagem, nem mesmo atenderam aos requisitos mínimos em relação à PNRS.

\section{Resultados e Discussão}

\subsection{Gestão dos Resíduos Sólidos}

Podemos definir a gestão de resíduos sólidos como sendo o desenvolvimento de ações intencionais e estratégicas de forma a lidar com os resíduos, destinando-os quando necessário. Também cabe destacar que a gestão de resíduos sólidos não é um fenômeno novo, é algo que é uma preocupação desde as civilizações da Antiguidade (Amaro, 2018).

A destinação adequada dos resíduos sólidos ocorre através de reuso, reaproveitamento, reciclagem e a adoção de uma economia circular, essas etapas são imprescindíveis para que o material seja valorizado em todo o processo, ainda cabe 
destacar a minimização dos impactos humanos sobre o meio ambiente, mas a adoção dessas ações é complexa, sobretudo pela falta de conhecimento e comunicação envolvendo diferentes atores (população, indústria e comércio), o problema é agravado pelo desconhecimento e comunicação insuficiente entres os diferentes atores envolvidos no processo. Como solução apontamos a necessidade de um vínculo entre a comunicação social e a educação ambiental, promovendo uma propaganda reflexiva e crítica que vise a conscientização do ser acerca de suas práticas para com o meio ambiente no cotidiano (Vieira e Beltrame, 2017).

\subsection{Caracterização e Quantificação dos Resíduos}

Faz-se necessário conhecer os diversos resíduos gerados em determinado ambiente, assim os processos de geração e manejo podem ser entendidos com mais clareza, pontos fortes e fracos em relação a cada tipo de gestão devem ser mensurados para que decisões assertivas sejam adotadas. Os resíduos produzidos por uma sociedade estão suscetíveis a uma série de variações em relação às épocas do ano, estilo de vida, movimento populacional sazonal (férias e fins de semana) (Garcia et al., 2016).

Quando todas as etapas da Política Nacional de Resíduos Sólidos são adotadas, os rejeitos são produzidos, um rejeito é o lixo que não pode mais passar por nenhum dos processos anteriormente apresentados (Bourscheidt et al., 2018). Quando isso ocorre, os rejeitos devem ser direcionados para um local onde ele possa ser descartado de modo adequado, como exemplo citamos os aterros sanitários, onde os resíduos sólidos são descartados de modo a atenuar os impactos do lixo no mundo (Garcia et al., 2016).

O plano de resíduos sólidos abrange um ciclo que tem princípio com a geração do resíduo, abarca também a identificação do ente gerador e o fim correto para o resíduo em consonância com a preocupação ambiental, passando pela responsabilização do setor público, titular (concessionário), do consumidor, do cidadão e do setor privado na busca de soluções que atuam a fim de extinguir efeitos negativos para a saúde pública e meio ambiente em cada fase do " ciclo de vida" dos produtos. (Brasil,2020).

O problema do lixo se verifica nas últimas décadas em virtude do vertiginoso crescimento populacional. De acordo com dados fornecidos pela última edição do estudo Panorama dos Resíduos Sólidos no Brasil, anualmente são gerados 71,60 milhões de toneladas de resíduos sólidos no Brasil, sendo que, dentre esse número cerca de 42,3 milhões de toneladas corresponde a resíduos sólidos urbanos, e cabe destacar que 59,1 \% é coletado para aterros sanitários (Abrelpe, 2017).

É alarmante citar que 29,30 milhões de toneladas de resíduos foram descartados de modo incorreto nos lixões, isso é preocupante, pois os lixões são estruturados sem a preocupação com os aspectos ambientais. O poder público muitas vezes não atua de modo mais efetivo através de investimentos públicos nos serviços vinculados a resíduos, há a necessidade de maior regulação e controle social, e deveria fomentar a coleta seletiva e recuperação de bens materiais. No tocante à gestão inadequada, vale destacar, que de acordo com o Panorama de Resíduos Sólidos no Brasil (Abrelpe,2017), não houve avanços significativos no que concerne aos Resíduos Sólidos Urbanos (RSU), prevalecendo a mesma proporção do ano anterior, isto é, a mesma de 2016.

No que concerne aos ambientes concordantes e inapropriados, cerca de 42,3 milhões de toneladas de Resíduos Sólidos Urbanos(RSU), o que corresponde a 59,1\% do lixo recolhido são depositados em aterros sanitários ;ao passo que 40,9\% dos resíduos colhidos foram jogados em determinada região inconveniente, perfazendo um total de 3.352 municípios brasileiros, mostrando um total de mais de 29 milhões de toneladas de resíduos em lixões ou autocontrole de aterros, onde um tripé de conhecimentos não condiz com o sistema e tudo é muito eventual ao meio ambiente no tocante à segurança, pois a destinação incorreta traz prejuízos à saúde de milhões de pessoas. No Brasil, $8 \%$ do lixo possui uma produção de 6,3 milhões de toneladas 
e ainda não é recolhido; e $40 \%$ do lixo é jogado nos lixões e aterros do Norte e Nordeste, onde há cerca de 37\% da população brasileira e os outros 50\% dos resíduos são depositados e recolhidos em lixões. (Abrelpe, 2019)

\subsection{Cidade Nordestina}

Inúmeras são as justificativas relativas à fragilidade dos municípios em relação aos RSU's, pode-se apontar problemas como recursos financeiros insuficientes, falta de planejamento, capacidade técnica sem preparo, modelo político-institucional ultrapassado, consumo elevado de produtos industrializados, o aumento da urbanização e ausência de educação ambiental que aborde a gestão de resíduos sólidos urbanos, esses são os problemas mais frequentes acerca dessa temática (Suzuki; Gomes, 2009; Fonseca, 2010; Silva, 2015; Brasil, 2017).

Para Araújo (2017), a elaboração do Plano Municipal de Gestão Integrada de Resíduos Sólidos - PGIRS é condição indispensável para o Distrito Federal e os municípios terem acesso aos recursos provenientes da União destinados à limpeza urbana e ao manejo de resíduos sólidos. Seu teor está disposto no art. 19 da Lei no 12.305/2010. Para municípios com população total inferior a vinte mil habitantes, o PGIRS terá conteúdo simples, segundo o constituído pelo Decreto 7.404/2010 que regulamenta a aludida lei.

Entretanto, em diversas cidades paraibanas e cearenses é notório o hábito de descartar seus resíduos em locais abertos, é um mau hábito atrelado à desinformação, pois é uma forma inadequada de descarte de resíduos sólidos domiciliares e comerciais (que oferecem baixo índice de poluição) estes são depositados juntamente com resíduos industriais e hospitalares (com alto risco de poluição) em terrenos baldios e que não tardam em se tornar lixões. No lixão, a disposição final de resíduos sólidos, caracterizada pela simples descarga dos resíduos sobre o solo, sem estratégias de proteção à natureza ou à saúde pública configuram-se como problemas alarmantes a serem contornados. Pois no lixão não há controle sobre o que é descartado e nem é levado em conta o tipo e o risco que o resíduo oferece. (Capim et al. 2018)

\subsection{Princípio básico de sustentabilidade}

Em conformidade com o modelo Triple Botton Line (Elkington: 1997), o primeiro princípio refere-se aos aspectos econômicos que se refere às variáveis que lidam com a linha de fundo e fluxo de caixa. O princípio social retrata as variáveis que lidam com a comunidade, isto é, educação, equidade, recursos sociais, saúde, bem-estar, qualidade de vida etc. O princípio ambiental acerca das variáveis ambientais relacionadas aos recursos naturais, qualidade da água e do ar, conservação da energia, uso do solo e defende que a sustentabilidade deve estar vinculada à proteção do ambiente, "já que manter (e em alguns casos, recuperar) o equilíbrio ambiental implica o uso racional e harmônico dos recursos naturais, de modo a por meio de sua degradação também não os levar ao seu esgotamento" (Silva, 2016, p. 8).

\subsection{Participação e Educação Social}

O planeta Terra tem cerca de sete bilhões de seres humanos, e 1,4 bilhões de toneladas de resíduos sólidos urbanos são gerados, o que equivale, em média a geração de 1,2 kg indivíduo/ dia. E neste cenário bastante alarmante, o Brasil situa-se como sendo um país com alta produção de resíduos, ele gera cerca de 80 milhões de toneladas por ano, no ano de 2016 alcançou a quarta colocação no ranking mundial. (Mello,2018).

Os impactos ambientais são preocupantes, diante deste problema, a Política Nacional de Resíduos Sólidos (PNRS), instituída pela Lei 12. 305/10 foi pensada para enfrentar os problemas diversos da gestão de resíduos sólidos e traçar diretrizes para o implemento de uma gestão de resíduos sólidos que não exerça impactos negativos no meio ambiente. Essa lei também 
possibilitou uma maior articulação envolvendo a União, Estados e Municípios, assim o setor produtivo e a sociedade agem em conjunto em prol de melhorias a curto e longo prazo (Brasil,2012).

Apesar dos avanços legais, somente no ano de 2010 uma lei específica foi elaborada para regular a temática de resíduos sólidos no país, trata-se da Lei Federal n 12.305, nela, a Política Nacional de Resíduos Sólidos foi instituída (Brasil, 2010), a supracitada lei contém uma série de princípios norteadores, objetivos, instrumentos e diretrizes intrínsecas à gestão integrada e ao gerenciamento de resíduos sólidos. De acordo com Pereira e Sousa (2017, p.190): “As normas previstas na lei representam um grande avanço na questão ambiental, pois impõe a obrigatoriedade, tanto por parte da sociedade, quanto por parte do Poder Público, de encontrar um destino adequado para o lixo". Conforme citado pelos autores, o cerne da relevância legal da lei em questão está centrado no compromisso e responsabilidade por parte da sociedade e do Poder Público, isso representa um progresso.

\subsection{Quantidade de lixões e aterros controlados que ainda recebem resíduos}

O marco legal do saneamento básico está disposto na Lei Federal n 14.026 , de 15 de julho de 2020, que atualizou e constituiu nova redação para o artigo 54 da PNRS (Política Nacional de Resíduos Sólidos), estipulando novos prazos, de forma escalonada, a fim de que os municípios assegurem disposição final ambientalmente apropriada aos resíduos sólidos, o último marco temporal seria data de 02 de agosto de 2024. Além da mencionada legislação, para demarcação das metas do indicador também se levou em conta o disposto na Lei Federal no 6.938/1981, na Lei Federal n 9.605/1999 e também na Lei Federal n 12.305/2010, que constituiu a PNRS. Assim, a partir de 2024, nenhum município deverá encaminhar seus resíduos para unidades impróprias. Os dados da tabela abaixo base do número de lixões e aterros controlados foram obtidos pelo Observatório dos Lixões da Confederação Nacional dos Municípios (CNM).

Tabela 1. Metas que estipulam prazos escalonados da implementação da PNRS no Brasil.

\begin{tabular}{c|c|c|c|c|c}
\hline \multirow{2}{*}{ REGIÃO } & \multicolumn{5}{|c}{ ANOS } \\
\cline { 2 - 6 } & $\mathbf{2 0 2 0}$ & $\mathbf{2 0 2 4}$ & $\mathbf{2 0 2 8}$ & $\mathbf{2 0 3 2}$ & $\mathbf{2 0 4 0}$ \\
\hline NORTE & $\mathbf{2 1 9}$ & $\mathbf{0}$ & $\mathbf{0}$ & $\mathbf{0}$ & $\mathbf{0}$ \\
\hline NORDESTE & $\mathbf{8 9 8}$ & $\mathbf{0}$ & $\mathbf{0}$ & $\mathbf{0}$ & $\mathbf{0}$ \\
\hline CENTRO-OESTE & $\mathbf{3 1 6}$ & $\mathbf{0}$ & $\mathbf{0}$ & $\mathbf{0}$ & $\mathbf{0}$ \\
\hline SUDESTE & $\mathbf{7 0 2}$ & $\mathbf{0}$ & $\mathbf{0}$ & $\mathbf{0}$ & $\mathbf{0}$ \\
\hline SUL & $\mathbf{2 6 3}$ & $\mathbf{0}$ & $\mathbf{0}$ & $\mathbf{0}$ & $\mathbf{0}$ \\
\hline BRASIL & $\mathbf{2 . 4 0 8}$ & $\mathbf{0}$ & $\mathbf{0}$ & $\mathbf{0}$ & $\mathbf{0}$ \\
\hline
\end{tabular}

Fonte: Adaptado do Observatório dos Lixões da Confederação Nacional dos Municípios (CNM).

Na tabela acima temos um mapa das regiões do Brasil, com dados disponibilizados pelo Observatório dos Lixões da Confederação Nacional dos Municípios (CNM), na coluna referente ao ano de 2020 disponibilizamos os dados referentes ao período do marco legal do saneamento básico cuja implementação e legalização está amparado pela Lei Federal n 14.026 , de 15 de julho de 2020; na próxima coluna temos o ano de 2024 que trata-se do último marco temporal para a implementação da PNRS, cuja prazo finda em 02 de agosto de 2024. Vale ressaltar que as demais datas, isto é, referentes aos anos de 2028, 2032 e 2040 são marcos temporais importantes para a implementação da PNRS nos municípios do Brasil.

\subsection{Exemplo de Cidades}

O estudo de Feitosa et al. (2018) se aproxima da problemática deste artigo, o enfoque principal do estudo realizado por eles se atém na instalação de um lixão no município de Iguatu-CE, para tanto, eles seguiram algumas etapas que foram essenciais na identificação e apontamento de soluções, os supracitados analisaram documentos, realizaram entrevistas, 
imbuídos pelo desejo de atender às demandas sociais, motivadas pela insatisfação da população local insatisfeita com os riscos ambientais que o lixão representava, os autores constataram de modo resoluto que "há necessidade de mudança de hábitos cotidianos e políticos para que se possa garantir uma convivência benéfica entre sociedade e natureza", assim o compromisso ambiental não depende só de políticas públicas ou apenas do esforço e conscientização da população, o que deve haver é uma somatória de esforços que visem atenuar, e se possível extinguir, paulatinamente o problema, levando em consideração a árdua tarefa que envolve poder público e sociedade, que ainda necessita de conscientização e práticas mais incisivas.

A tecnologia tem sido empregada para solucionar os problemas dos lixões, citamos por exemplo, a tecnologia aplicada à reciclagem, ela está vinculada à preservação do meio ambiente, este processo reduz a exploração dos recursos naturais. Cabe destacar também que a reciclagem é uma alternativa financeira para os catadores, que buscam materiais reutilizáveis e recicláveis, mesmo correndo risco de saúde pelo contato com o lixo, sofrendo o estigma do preconceito social eles exercem a catação como sendo uma atividade econômica a fim de obter o sustento próprio e de sua família (Silveira; Nogueira; Fernandes, 2017). Há várias práticas sustentáveis como a coleta seletiva. A separação de Resíduos Sólidos (RS) de modo correto é imprescindível, pois a comercialização dos resíduos sólidos reutilizáveis e recicláveis gera renda, preserva o meio ambiente e contribui para a cultura local.

O Brasil é marcado por profundas desigualdades até mesmo no tocante ao serviço de coleta de Resíduos Sólidos (RS). A região Nordeste é a macrorregião mais alarmante, pois o pior índice de coleta de resíduos sólidos (79\%) pertence a essa região, a região Sudeste (a mais desenvolvida do país), por exemplo, tem um índice de 98\%, índices discrepantes, até mesmo em relação às outras regiões o Nordeste é muito deficitário neste ponto, para fins de comparação disponibilizamos outros dados que remetem às regiões Sul, Centro-Oeste e Norte, que apresentam, respectivamente, 95\%, 94\% e 81\%. No que diz respeito à coleta seletiva, apenas 49,6\% dos municípios do Nordeste apresentam alguma iniciativa (ABRELPE, 2016). No tocante à Paraíba e ao Ceará, um dos Estados que compõe o Nordeste, a mesma realidade alarmante é verificada quando o assunto é o gerenciamento de Resíduos Sólidos (RS), coleta e disposição (ABRELPE, 2016).

\section{Considerações Finais}

Tendo analisado todos os pontos relativos à gestão dos resíduos sólidos, é manifesto que é um tema indispensável para o sucesso não só da região Nordeste, mas de todo o país. Portanto, temos que incentivar a inclusão da educação ambiental na estrutura curricular do ensino nas escolas, informar os educandos sobre o tema, através de propagandas, palestras e adotar tecnologias sociais para a gestão dos resíduos.

A gestão de resíduos é uma ferramenta necessária para o êxito socioambiental dos municípios do Nordeste, é um tema que ainda carece de maior divulgação na região supracitada tendo em consideração os resultados da região Nordeste bastante atrasados em relação às outras regiões do país como tratados ao longo do estudo.

Na região Nordeste, um dos maiores problemas é sem dúvida a estiagem, constituindo-se como principal desafio a ser superado, a gestão de resíduos sólidos é desafiadora, assim é necessário a adoção da gestão de resíduos sólidos também na zona rural tendo em consideração a seca; e também a gestão de resíduos sólidos nos ambientes urbanos.

A fim de solucionar problemas em relação ao descarte do lixo, houve a criação do Plano Nacional dos Resíduos Sólidos, que contempla a reciclagem, aspectos socioambientais, estaduais, municipais, bem como as comunidades rurais. O conhecimento acerca do descarte correto dos resíduos sólidos proporciona melhorias e norteia a produção e o destino do lixo.

O principal escopo deste artigo concentrou-se em apontar soluções em relação à gestão de resíduos sólidos no Ceará e na Paraíba, visando assim contribuir para uma maior compreensão do tema tratado, apontar medidas e identificar problemas. Visamos colaborar para uma maior conscientização e criticidade sobre os impactos socioambientais, a adoção de uma boa 
gestão de resíduos sólidos contribui para uma educação de qualidade e para a geração de empregos em vários setores do Nordeste, desde as pequenas comunidades rurais à indústria. Em virtude de ser um tema não muito trabalhado, sugerimos a realização de mais pesquisas e estudos sobre a temática da geração de resíduos e seus impactos no Nordeste.

A gestão de resíduos sólidos é capaz de monitorar o impacto do lixo, e este é uma importante variável e indicador de sustentabilidade, a adoção da gestão de resíduos sólidos gera benefícios a curto e a longo prazo, pois sua adoção e correta aplicação beneficiará as gerações futuras. Mas para tanto, faz-se mister a adoção de políticas públicas e incentivos privados e uma maior divulgação das informações visando a conscientização sobre o tema.

Ao analisar todos os pontos da gestão dos resíduos sólidos, é visível e de extrema importância para o crescimento do nosso país a adoção de ações que favoreçam o apropriado gerenciamento dos resíduos sólidos. Por essa razão temos que continuar a insistir na inclusão da educação ambiental na estrutura curricular de nossas escolas e adoção de tecnologias sociais para gestão dos resíduos.

A gestão do resíduo é uma ferramenta essencial nos municípios nordestinos, é um tema que não deve ser visto como insignificante, sobretudo porque este tema deve ser amplamente discutido e trabalhado de modo holístico em todos os eixos sociais, por se tratar do futuro da humanidade.

Sem dúvida um dos maiores desafios da região Nordeste é a seca, mas um dos maiores desafios que não deve ser ignorado no Nordeste diz respeito à gestão dos resíduos sólidos em ambientes urbanos. A formação de um Plano Nacional de Resíduos Sólidos só destaca a urgência em se trabalhar ações como a reciclagem, fomentar a preocupação socioambiental nos estados, municípios e comunidades, pois o conhecimento aplicado à gestão de resíduos sólidos traz inúmeros benefícios em relação ao valor, produção e destino apropriado a fim de evitar danos ao meio-ambiente.

A necessidade em se trabalhar a gestão de resíduos sólidos instigou a criação do presente artigo com o fito de tratar do grave problema gerado pelo descarte inadequado dos resíduos sólidos, estudos e políticas voltados a essa temática embasaram este estudo, apesar de haver mudanças positivas em relação ao gerenciamento de resíduos sólidos e políticas públicas e planos cuidadosamente elaborados, a implementação de uma gestão de resíduos sólidos encontra uma série de óbices, desde problemas financeiros até um correto destino.

As soluções que apontamos de modo sucinto visam promover uma mudança educacional e a adoção de práticas salutares pela população em geral, somente com as corretas informações, ferramentas, manejos e destinação apropriados dos resíduos o Nordeste conseguirá reverter o quadro preocupante e deficitário em relação ao problema tratado neste artigo.

Como exemplo de uma PNRS de sucesso podemos citar o projeto de Tratamento de Resíduos do Vale do Acaraú: a Central de Tratamento de Resíduos Sólidos de Sobral, há também seis estações de tratamento de resíduos sólidos no Noroeste do estado do Ceará como a de Coreaú, Ubaúna, Forquilha, Pacujá, Massapê e Cariré, além disso, Sobral possui mais três centrais municipais de reciclagem, apesar dos desafios inerentes ao impacto gerado pelo descarte incorreto do lixo, a região Noroeste do Ceará, e mais especificamente o Vale do Acaraú mostra seu potencial na implementação da Política Nacional dos Resíduos Sólidos, para tanto, é necessário o esforço recíproco entre o Poder Público e a conscientização da população acerca de seu papel a fim de garantir a reciclagem, reutilização e a gestão integral dos resíduos.

Por ser um tema incipiente, atual e cujos trabalhos ainda são escassos, sugerimos futuras pesquisas, a fim de que o tema, cuja relevância é indispensável aos nossos tempos seja mais trabalhado e desenvolvido, e assim possamos viver em uma sociedade mais harmoniosa com o meio ambiente, evitando impactos socioambientais, e promovendo um despertar consciente, crítico e reflexivo em todo o país, sobretudo na região Nordeste. 
Research, Society and Development, v. 10, n. 11, e217101119431, 2021

(CC BY 4.0) | ISSN 2525-3409 | DOI: http://dx.doi.org/10.33448/rsd-v10i11.19431

\section{Agradecimentos}

Gostaria de externar a minha profunda gratidão a todos os que colaboraram para a construção deste artigo, em especial o trabalho ímpar e dedicado de Rayan Gomes, José Levi Chaves, Farrapo Portela.

\section{Referências}

Amaro, A. B. (2018). Política Nacional de Resíduos Sólidos, uma lei viável?: estudo de caso a partir do âmbito do acordo MPF/MPSP x CESP.

AMBIENTAL. Veredas do Direito: Direito Ambiental e Desenvolvimento Sustentável, 17(39).

Araújo, L. P. D. S. (2017). Análise da eficiência técnica da prestação dos serviços de coleta de resíduos sólidos urbanos nos municípios paraibanos

Araújo, L. P. D. S. (2017). Análise da eficiência técnica da prestação dos serviços de coleta de resíduos sólidos urbanos nos municípios paraibanos.

Bezerra, A. K. L., Rocha, P. H. F., \& Neto, J. M. M. (2020). Resíduos sólidos: a má gestão pública como problema

Bourscheidt, D. M., Borges, C. L. P., Rodrigues, A., \& Stoffel, J. (2018). Sustentabilidade e resíduos sólidos: diagnóstico e saberes populares auxiliando no destino correto dos resíduos. Brazilian Journal of Development, 4(6), 2730-2749.

BRASIL, C. (2010). Lei n ${ }^{\circ}$ 12.305, de 2 de agosto de 2010. Institui a Política Nacional de Resíduos Sólidos; altera a Lei nº 9.605 , de 12 de fevereiro de 1998; e dá outras providências. Diário Oficial da União, 3-3.

Bueno, E. U. (2012). Brasil: uma história: cinco séculos de um país em construção. Leya.

Civil, C. (2018). Avaliação de políticas públicas: guia prático de análise ex post. Brasília: Casa Civil da Presidência da República.

Da Silva Neto, A. C. A inclusão laboral dos catadores de materiais recicláveis e reutilizáveis. Conselho editorial.

Dantas, R. D., dos Santos, D. P., \& de Carvalho Lima, J. E. (2018). A influência da gestão financeira no desempenho dos microempreendedores individuais da Cidade de Juazeiro do Norte-CE. Revista Interfaces: Saúde, Humanas e Tecnologia, 5(15), 02-10.

de Andrade, I. R., \& Pereira, L. D. (2020). Aplicabilidade dos sistemas nacionais de informação como instrumento de gestão

de Freitas, L. C., Besen, G. R., \& Jacobi, P. R. (2013). Panorama da implementação da Política Nacional de Resíduos Sólidos: resíduos urbanos. Política

De Goiás, A. L. D. E. (2018). ABRELPE. Associação Brasileira de Empresas de Limpeza Pública e Resíduos Especiais. Panorama dos Resíduos Sólidos no Brasil. São Paulo, 2017. Disponível. Centro Universitário de Anapólis-Unievangélica Programa de Pós-graduação em Sociedade, Tecnologia e Meio Ambiente (PPSTMA), 17.

de GOIÁS, A. L. D. E. (2018). ABRELPE. Associação Brasileira de Empresas de Limpeza Pública e Resíduos Especiais. Panorama dos Resíduos Sólidos no Brasil. São Paulo, 2017. Disponível. Centro Universitário de Anapólis-UniEVANGÉLICA Programa de Pós-Graduação Em Sociedade, Tecnologia e Meio Ambiente (PPSTMA), 17.

De Paula Pereira, M., \& Souza, K. S. (2017). Política nacional de resíduos sólidos (PNRS): avanços ambientais e viés social nos municípios de pequeno porte. Ciências Sociais Aplicadas em Revista, 17(32), 189-210.

de Souza Araújo, L. P., da PAIXÃO, A. N., \& Paixão, M. C. S. Análise da eficiência técnica da prestação dos serviços de coleta de resíduos sólidos urbanos nos municípios paraibanos.

Do Esgotamento Sanitário: applicability of national information systems as an instrument for the management

dos Santos Garcia, M. B., Neto, J. L., Mendes, J. G., de Freitas Xerfan, F. M., de Vasconcellos, C. A. B., \& Friede, R. R. (2016). Resíduos sólidos: responsabilidade compartilhada. Semioses, 9(2), 77-91

dos Santos, J. E. D. S., van Elk, A. G. H. P., \& Ferreira, J. A. (2021). Gestão de resíduos sólidos dos maiores geradores da Região Metropolitana do Rio de Janeiro. Brazilian Journal of Development, 7(3), 31760-31446.

Feitosa, A. K., Turatti, L., Brod, F. P., Barden, J. E., \& Konrad, O. (2018). Conflito socioambiental na gestão de resíduos sólidos

Fernandes, J. L., Qualharini, E. L., da Cunha Fernandes, A. S., \& Cabral, J. C. (2016). Um estudo sobre a política nacional de resíduo sólido e o impacto ambiental. Projectus, 1(1), 52-57.

Ludke, M.; Andre, M. E. D. A. Pesquisa em educação: uma abordagem qualitativa. ( 2.ed.) EPU, 2013.

Mello, J. O., Ribeiro, V. M. O., Lotta, G. S. O., Bonamino, A. O., \& Carvalho, C. P. D. O. (2020). Implementação de políticas e atuação de gestores públicos: experiências recentes das políticas de redução das desigualdades.

Nacional De Resíduos Sólidos: Implementação E, 11.

Of Sanitary Sewage. Ignis: Periódico Científico de Arquitetura e Urbanismo, Engenharias e Tecnologia da Informação, 82-98. 
Research, Society and Development, v. 10, n. 11, e217101119431, 2021 (CC BY 4.0) | ISSN 2525-3409 | DOI: http://dx.doi.org/10.33448/rsd-v10i11.19431

Oliveira, H. S. D. Tesouro do Lixo: Construção de uma sociedade Sustentável diante dos parâmetros estabelecidos na Lei $12.305 / 2010$ Que institui a Política Nacional de Resíduos Sólidos.

Oliveira, T. B. D., \& Galvão, A. D. C. (2016). Planejamento municipal na gestão dos resíduos sólidos urbanos e na organização da coleta seletiva. Engenharia Sanitária e Ambiental, 21, 55-64.

Ramos, N. F., Gomes, J. C., Castilhos, A. B., \& Gourdon, R. (2017). Desenvolvimento de ferramenta para diagnóstico ambiental de lixões de resíduos sólidos urbanos no Brasil. Engenharia Sanitaria e Ambiental, 22, 1233-1241.

Ramos, N. F., Gomes, J. C., Castilhos, A. B., \& Gourdon, R. (2017). Desenvolvimento de ferramenta para diagnóstico ambiental de lixões de resíduos sólidos urbanos no Brasil. Engenharia Sanitaria e Ambiental, 22, 1233-1241.

Rezende, J. M. D. (2009). À sombra do plátano: crônicas de história da medicina.

Rocha, P. V. D. L. (2020). Análise da gestão de resíduos sólidos urbanos no Cariri Ocidental da Paraíba (Master's thesis, Universidade Federal do Rio Grande do Norte).

Rocha, P. V. D. L. (2020). Análise da gestão de resíduos sólidos urbanos no Cariri Ocidental da Paraíba (Master's thesis, Universidade Federal do Rio Grande do Norte).

Rusconi, C. (2003). Dicionário do grego do Novo Testamento. São Paulo: Paulus.

Severino, A. J. (2016). Metodologia do trabalho científico. Cortez editora.

Silveira, C. A., Nogueira, L. M., \& Fernandes, K. S. (2017). Perception of quality of life of solid waste segregators. Journal of Nursing UFPE on line, 11(7), 2718-2727.

Souza, S. D. O. D. (2019). A Lei n 12.305/10: um estudo sobre a gestão de resíduos sólidos no município de Várzea Alegre-CE.

Souza, s. d. o. d. (2019). a lei n 12.305/10: um estudo sobre a gestão de resíduos sólidos no município de Várzea Alegre-CE.

Teixeira, J. C. M., \& de Araújo, M. A. D. (2020). Implementação do Plano Municipal de Gestão Integrada de Resíduos Sólidos no Município de Natal (Rn): O Papel dos Atores. Administração Pública e Gestão Social.

Urbanos: estudo de caso em Iguatu, Ceará, Brasil. Revista Gestão \& Sustentabilidade Ambiental, 7(1), 345-362.

Vieira, P. L., Beltrame, L. T. C., Ximenes, T. C. F., Da Silva, R. G., \& El-Deir, S. G. (2017). Educação ambiental: a resposta para o problema de resíduos sólidos urbanos. Resíduos Sólidos e Recursos Hídricos. 